\title{
Carbon nanotube composites for glucose biosensor incorporated with reverse iontophoresis function for noninvasive glucose monitoring
}

\author{
Tai-Ping Sun ${ }^{1,2,5}$ \\ Hsiu-Li Shieh ${ }^{2}$ \\ Congo Tak-Shing Ching ${ }^{1,2,5}$ \\ Yan-Dong Yao ${ }^{3}$ \\ Su-Hua Huang ${ }^{4}$ \\ Chia-Ming Liu' \\ Wei-Hao Liu' \\ Chung-Yuan Chen² \\ 'Graduate Institute of Biomedicine \\ and Biomedical Technology, \\ ${ }^{2}$ Department of Electrical Engineering, \\ National Chi Nan University, Nantou, \\ Taiwan, ROC; ${ }^{3}$ Department of Applied \\ Biology and Chemical Technology, The \\ Hong Kong Polytechnic University, \\ Hung Hom, Hong Kong; ${ }^{4}$ Department \\ of Biotechnology, Asia University, \\ Taichung, Taiwan, ROC; ${ }^{5}$ These authors \\ contributed equally to this work
}

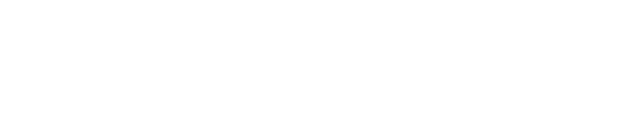

\begin{abstract}
This study aims to develop an amperometric glucose biosensor, based on carbon nanotubes material for reverse iontophoresis, fabricated by immobilizing a mixture of glucose oxidase (GOD) and multiwalled carbon nanotubes (MWCNT) epoxy-composite, on a planar screen-printed carbon electrode. MWCNT was employed to ensure proper incorporation into the epoxy mixture and faster electron transfer between the GOD and the transducer. Results showed this biosensor possesses a low detection potential $(+500 \mathrm{mV})$, good sensitivity $(4 \mu \mathrm{A} / \mathrm{mM})$ and an excellent linear response range $\left(r^{2}=0.999 ; 0-4 \mathrm{mM}\right)$ of glucose detection at $+500 \mathrm{mV}$ (versus $\mathrm{Ag} / \mathrm{AgCl}$ ). The response time of the biosensor was about $25 \mathrm{~s}$. In addition, the biosensor could be used in conjunction with reverse iontophoresis technique. In an actual evaluation model, an excellent linear relationship $\left(r^{2}=0.986\right)$ was found between the glucose concentration of the actual model and the biosensor's current response. Thus, a glucose biosensor based on carbon nanotube composites and incorporated with reverse iontophoresis function was developed.
\end{abstract}

Keywords: amperometric, carbon nanotubes, glucose monitoring, biosensors, reverse iontophoresis

\section{Introduction}

The discovery of carbon nanotube (CNT) in 1991, led to many new technical developments and applications because of the characteristics of large surface area, unique electronic properties, and relatively high mechanical strength associated with it. ${ }^{1}$ Recent studies demonstrated high electrocatalytic effect and fast electron-transfer rate in CNT material ${ }^{2-6}$ and thereby provide a new material for fabricating biosensors. ${ }^{7,8}$ Moreover, CNT can reduce the surface fouling on electrochemical devices without a mediator. The ability of CNT in facilitating electron transfer of hydrogen peroxide $\left(\mathrm{H}_{2} \mathrm{O}_{2}\right)$ shows great promise as oxidase-based amperometric biosensors. ${ }^{6,9}$ To the best of our knowledge there is no report on the use of CNT composites in glucose biosensor, incorporated with reverse iontophoresis function, for noninvasive glucose monitoring.

Reverse iontophoresis is a technique using a small electric charge to extract both charged and neutral molecules through the skin, recently used for patient monitoring. ${ }^{10-15}$ The authors only found reports of a glucose sensor integrated with reverse iontophoresis function. ${ }^{11,14-30}$ This glucose biosensor, approved by the US Food and Drug Administration, is GlucoWatch ${ }^{\circledR}$ biographer, which passes a small 
current between two skin-surface hydrogel electrodes to extract glucose-containing interstitial fluid into hydrogel pads, incorporating a glucose oxidase (GOD) biosensor. ${ }^{14,17,31}$ Unfortunately, GlucoWatch causes several problems, such as skin irritation or rash under the device in a number of patients. This problem may be due to the immobilization of GOD inside the hydrogel pads releasing peroxide. Even worse, GlucoWatch is unreliable in detecting hypoglycemia and hyperglycemia. ${ }^{16}$

The aim of this study is thus to find out the optimum combination of multiwalled carbon nanotubes and GOD for a glucose biosensor, in order to develop a new glucose biosensor incorporated with reverse iontophoresis function for noninvasive glucose monitoring. The glucose biosensor for reverse iontophoresis was eventually evaluated in this study.

\section{Materials and methods}

\section{Reagents and solutions}

All reagents used in this study, were commercially available and used without further purification: GOD (type VII), $\beta-\mathrm{D}(+)$ glucose, phosphate buffered saline, multiwalled carbon nanotubes (MWCNT, 0.5-50 $\mu \mathrm{m},>95 \%$ purity) powders were purchased from Sigma Chemical Co. (St. Louis, MO, USA); Methylcellulose (MC, Methocel A4M Prem) from Dow Chemical Co. (Midland, MI, USA). Deionized water purified by a Millipore System (Milli-Q UFplus; Bedford, MA, USA) was used to prepare all solutions. Graphite paste, silver paste, silver-silver chloride $(\mathrm{Ag} / \mathrm{AgCl})$ paste, and insulating paste were purchased from Advanced Conductive
Materials (Atascadero, CA, USA). Epoxy (EPO-TEK ${ }^{\circledR}$ 509FM-1) was purchased from Epoxy Technology (Billerica, MA, USA). Polyethylene terephthalate (PETE) sheet was purchased from $3 \mathrm{M}$.

\section{Construction of the glucose biosensor}

The construction steps of a planar three-electrode transducer were shown schematically in Figure 1, according to the procedure described earlier. ${ }^{32}$ The transducer was then used for glucose biosensor construction.

A biocomposite paste was prepared by mixing MWCNT (18.0\%-19.5\% w/w) with GOD $(0.5 \%-2.0 \% \mathrm{w} / \mathrm{w})$, followed by the incorporation of epoxy $(80.0 \% \mathrm{w} / \mathrm{w})$ and further 30 minutes mixing, in order to obtain a homogeneous biocomposite paste. This paste $(10 \mu \mathrm{L})$ was then coated onto the surface of a graphite pad (working electrode) of the transducer and dried for 3 days at $30^{\circ} \mathrm{C}$. Unused glucose biosensors were kept in the dark at $4^{\circ} \mathrm{C}$.

\section{Hydrodynamic voltammetry measurements of the glucose biosensor}

Using an electrochemical interface (electrochemical interface SI1286, Schlumberger Technologies, England), measurements were taken at $25^{\circ} \mathrm{C}$ with the biosensor in a solution of $4 \mathrm{mM}$ glucose in $0.1 \mathrm{M}$ phosphate buffer (pH 7.0) subjected to constant stirring. Incremental potentials $(0-1000 \mathrm{mV}, 100 \mathrm{mV}$ increments) versus $\mathrm{Ag} / \mathrm{AgCl}$ pad were applied to the working electrode of the biosensor and the current responses of the biosensor to glucose were measured.

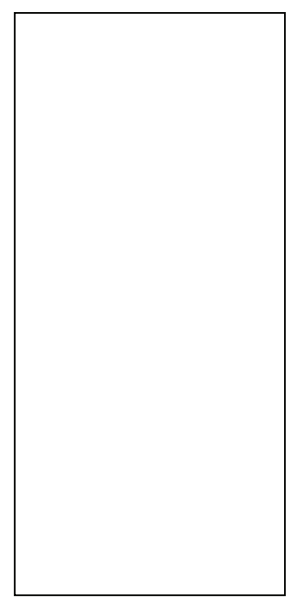

(a)

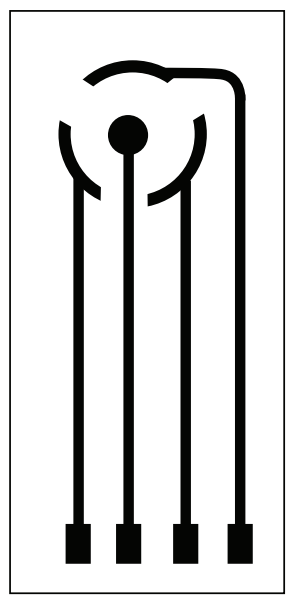

(b)

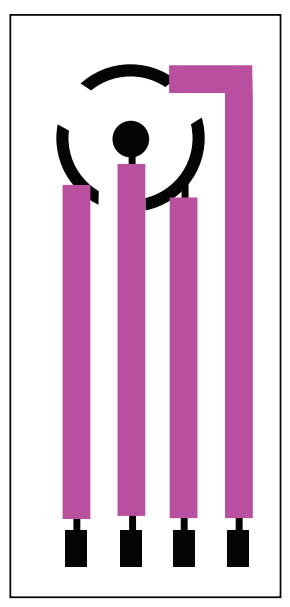

(c)

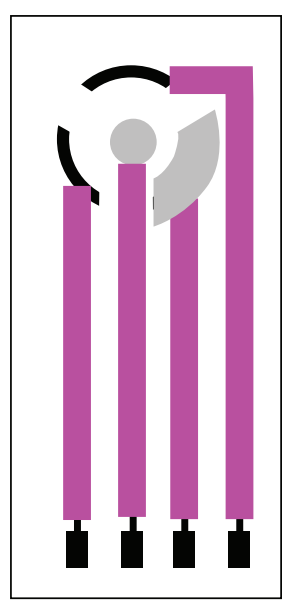

(d)

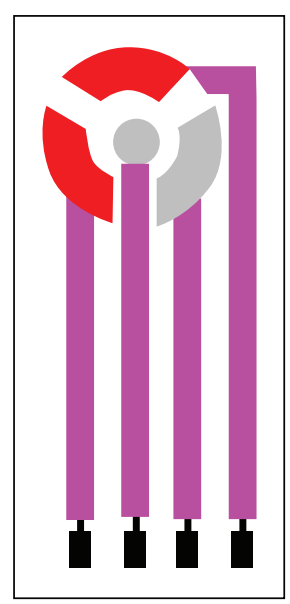

(e)

Figure I Construction steps for the planar configuration of the screen-printed transducer. a) (PETE) support material; b) conducting silver basal track; c) insulation layer; d) $\mathrm{Ag} / \mathrm{AgCl}$ pads, the iontophoresis electrode (the central circular one) for reverse iontophoresis and the reference electrode; e) graphite pads, the working and counter electrodes. 


\section{Measurements of the biosensor current response to glucose}

Measurements were carried out at $25^{\circ} \mathrm{C}$ at the electrochemical interface. The biosensor was placed in a cell containing $0.1 \mathrm{M}$ phosphate buffer solution $\mathrm{pH} 7.0$, subjected to constant stirring, employed as supporting electrolyte. An applied potential of $+500 \mathrm{mV}$ versus $\mathrm{Ag} / \mathrm{AgCl}$ pad was applied to the working electrode of the biosensor. After the background current stabilized, different glucose solution was added to the constantly-stirred buffer solution and the current response of the biosensor to glucose was then measured.

\section{Evaluation of the ferrocene-mediated glucose biosensor for reverse iontophoresis}

A $90 \mu \mathrm{L}$ of a $4 \% \mathrm{MC}$ gel (prepared by mixing $4 \mathrm{~g}$ of $\mathrm{MC}$ with $100 \mathrm{~mL}$ of $0.1 \mathrm{M}$ phosphate buffer $\mathrm{pH}$ 7.0) was laced onto two biosensors made up of optimum combination of MWCNT $(18.0 \% \mathrm{w} / \mathrm{w})$ and GOD $(2.0 \% \mathrm{w} / \mathrm{w})$. The two biosensors were then fixed onto the nanoporous membrane (Spectra/Por ${ }^{\circledR}$ CE, MWCO: 500, Spectrum Laboratories, Inc., Canada) of our custom-developed diffusion cell, ${ }^{33}$ filled with different concentrations of glucose solutions, and the iontophoresis electrode center of the biosensors was $23 \mathrm{~mm}$ apart. Using our custom-developed reverse iontophoresis device ${ }^{34}$ at room temperature $\left(22-24^{\circ} \mathrm{C}\right)$, a bipolar current $\left(0.3 \mathrm{~mA} / \mathrm{cm}^{2}\right.$, period $=30$ minutes, ie, $\left.555.6 \mu \mathrm{Hz}\right)$ was passed between the iontophoresis electrodes for 90 minutes. At the end of the experiment, biosensors were connected to the electrochemical interface for current response measurement and an applied potential of $+500 \mathrm{mV}$ versus $\mathrm{Ag} / \mathrm{AgCl}$ pad was applied to the working electrode.

\section{Results and discussion \\ The amperometric transducer}

Good inert behavior of the counter electrode is very important and hence elements such as gold and platinum are commonly used. ${ }^{35,36}$ On the other hand, there is no report of any meaningful relationship between current density and the materials used and their geometries. ${ }^{37}$ Therefore graphite, an inert material, was used as counter electrode material in this study based on their availability and affordability.

The ratio of counter electrode area to working electrode area $\left(A_{C} / A_{W}\right)$, can exert influence on the supply of determined current to the working electrode without limiting its response. ${ }^{38}$ The optimal $\mathrm{A}_{\mathrm{C}} / \mathrm{A}_{\mathrm{W}}$ ratio was reported to be in the range of 1 and $12 .{ }^{39-43}$ Composite material used in this study allows fabrication of an inert graphite counter electrode with an $A_{C} / A_{W}$ ratio of at least 0.125 . Furthermore, there is no great difference between the current density of transducer constructed with $A_{C} / A_{W}$ ratio 0.11 and 9.20. ${ }^{37}$ Therefore the $A_{C} / A_{W}$ ratio of 1 was employed on constructing the amperometric transducer in this study.

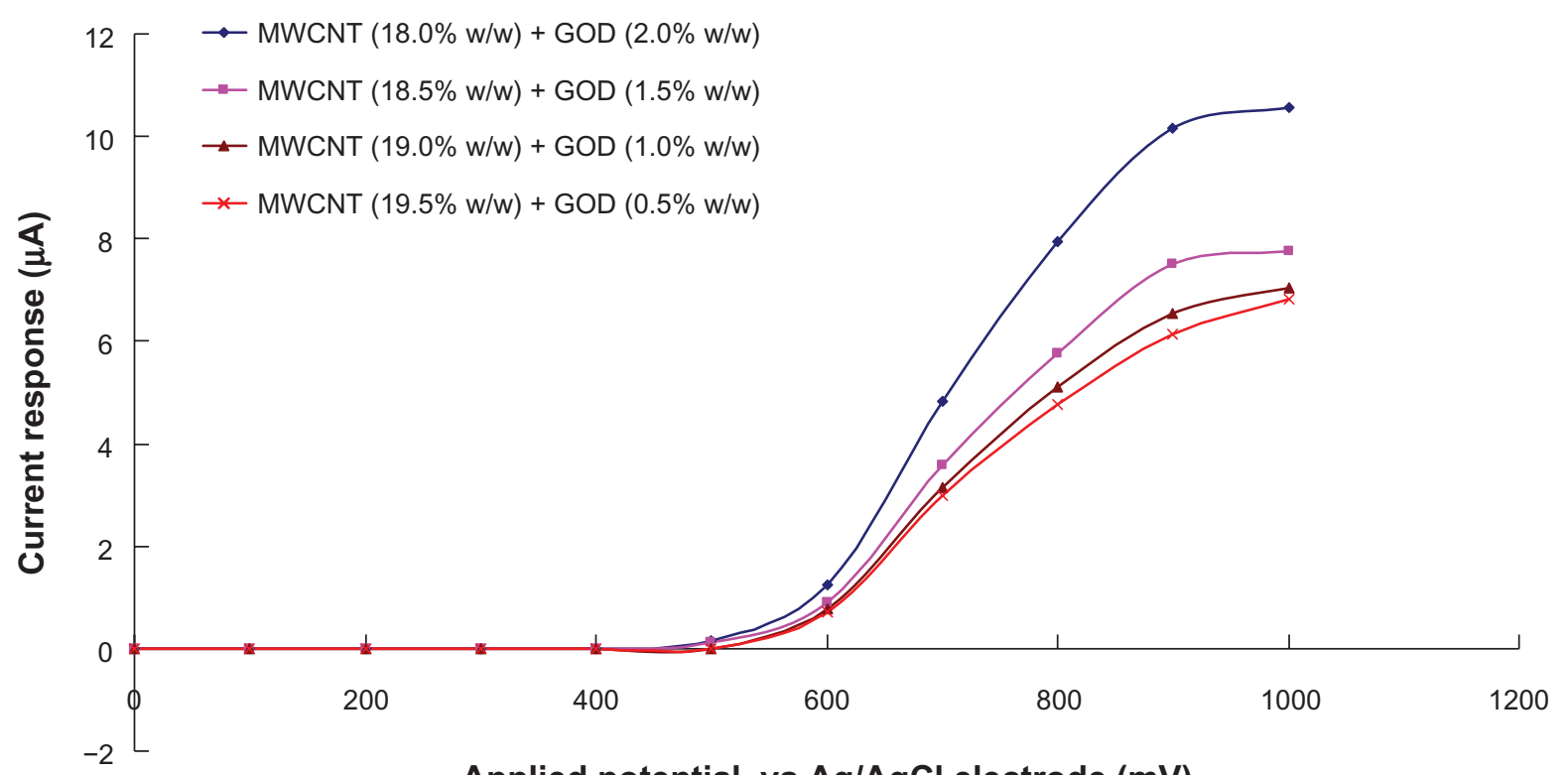

Applied potential vs $\mathrm{Ag} / \mathrm{AgCl}$ electrode $(\mathrm{mV})$

Figure 2 Hydrodynamic voltammogram of the biosensors in constantly-stirred solution of $4 \mathrm{mM}$ glucose with $0.1 \mathrm{M}$ phosphate buffer ( $\mathrm{pH} 7.0$ ). Abbreviations: GOD, glucose oxidase; MWCNT, multiwalled carbon nanotubes. 


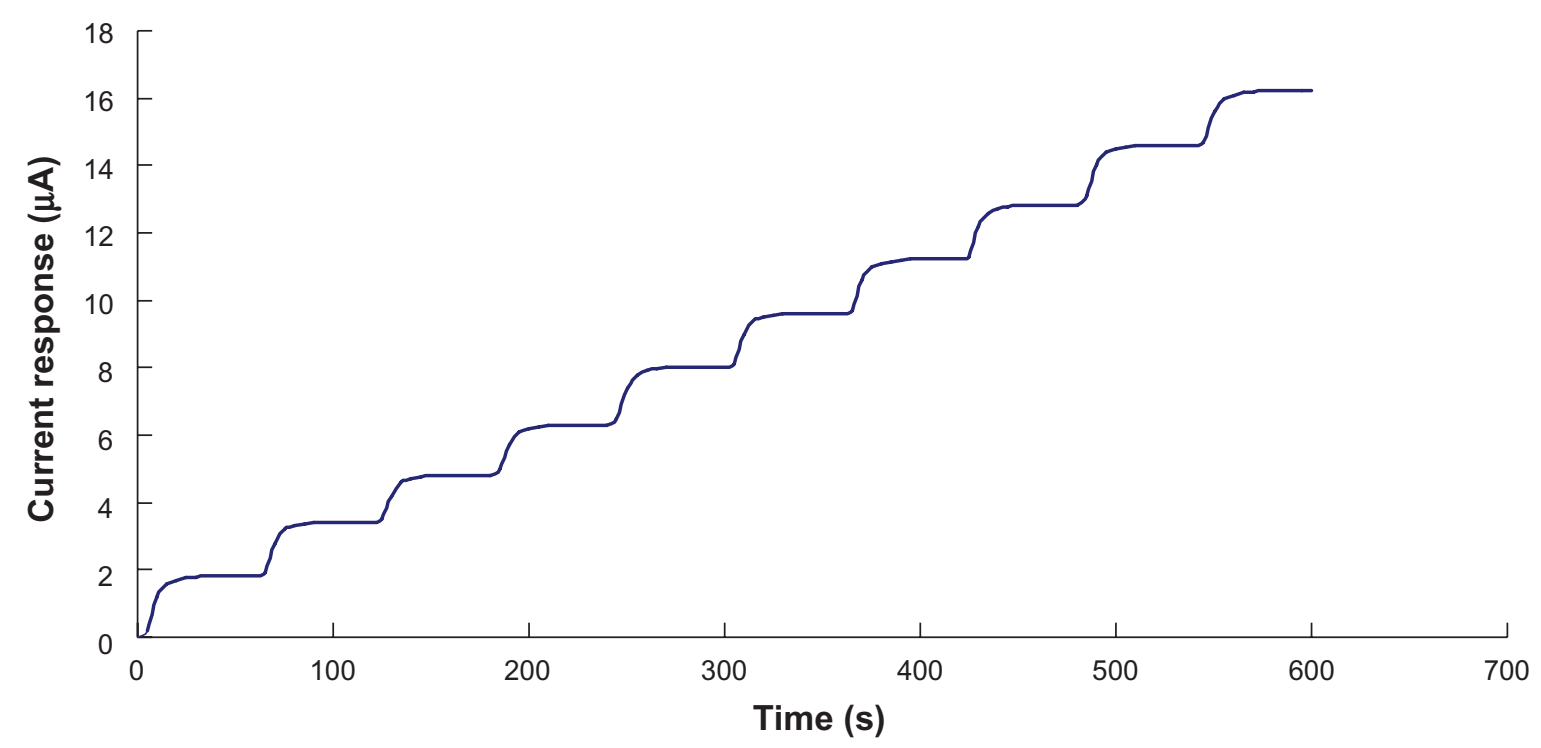

Figure 3 Current-time curve obtained by successive addition of $4 \mathrm{mM}$ glucose solution to the biosensor. Data is obtained from biosensor with the combination of MWCNT $(18.0 \% \mathrm{w} / \mathrm{w})$ and GOD $(2.0 \% \mathrm{w} / \mathrm{w})$.

Abbreviations: GOD, glucose oxidase; MWCNT, multiwalled carbon nanotubes.

\section{Hydrodynamic voltammogram of the glucose biosensor}

Several reports ${ }^{7,8}$ have suggested that carbon nanotube can significantly facilitates catalytic effect, both on the reduction and oxidation of hydrogen peroxide $\left(\mathrm{H}_{2} \mathrm{O}_{2}\right)$, making it highly sensitive in detection of $\mathrm{H}_{2} \mathrm{O}_{2}$. Figure 2 illustrated the hydrodynamic voltammogram of the biosensors at a constantly-stirred solution of $4 \mathrm{mM}$ glucose in $0.1 \mathrm{M}$ phosphate buffer ( $\mathrm{pH}$ 7.0). It was found that the oxidation currents generated by the biosensors begin at potential about $+500 \mathrm{mV}$. Carbon nanotube therefore can significantly facilitate the electron transfer between $\mathrm{H}_{2} \mathrm{O}_{2}$ molecules. ${ }^{7.8}$ Moreover, carbon nanotube promotes the low oxidation potential amperometric determination of glucose. As shown in Figure 2, biosensor with the combination of MWCNT $(18.0 \% \mathrm{w} / \mathrm{w})$ and GOD $(2.0 \% \mathrm{w} / \mathrm{w})$ is optimal for detecting and generating glucose signals, than mixture with other ratios.

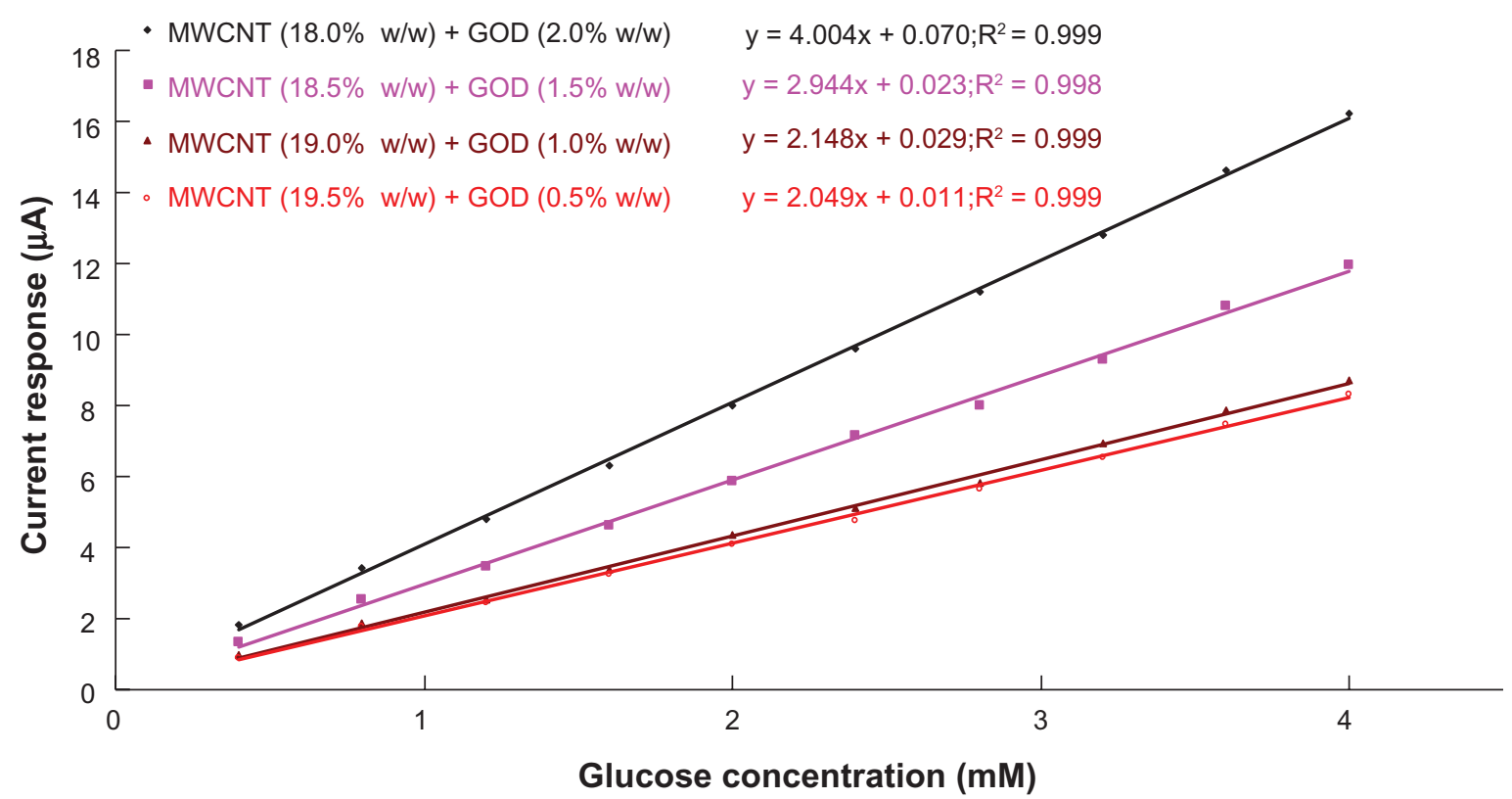

Figure 4 Calibration curves of the biosensors to glucose concentration. The lines are best fit found by linear regression. Sensitivity of the biosensor is indicated by the slope of the linear regression line.

Abbreviations: GOD, glucose oxidase; MWCNT, multiwalled carbon nanotubes. 


\section{Calibration of the biosensor to glucose}

Figure 3 showed a current-time curve, where steps correspond to current response of the biosensor (MWCNT $[18.0 \% \mathrm{w} / \mathrm{w}]$ and GOD $[2.0 \% \mathrm{w} / \mathrm{w}]$ mixture $)$ at the applied potential of $+500 \mathrm{mV}$, for successive additions of $4 \mathrm{mM}$ glucose in $0.1 \mathrm{M}$ phosphate buffer solution ( $\mathrm{pH} 7.0$ ). Immediately after the addition of glucose solution, the reductive current increased and reached $95 \%$ of the steady state current at about 25 seconds. The response time of our biosensor is comparable to that reported by Antiochia and Gorton. ${ }^{44}$

From the data of current-time curves, the magnitude of current response was plotted against the glucose concentration (see Figure 4) and the sensitivity of the biosensor was determined by the slope of linear regression of this current response versus glucose concentration. The current response is directly proportional to the glucose concentration over a wide range of concentration $(0-4 \mathrm{mM})$, where correlation coefficient is greater than 0.997. Since the amount of transdermal glucose extraction by reverse iontophoresis is in the order of $\mu \mathrm{M},{ }^{28}$ the range of measurement of glucose biosensor designed in this study can detect the normal concentrations of transdermally extracted glucose with good accuracy.

Biosensor constructed with MWCNT $(18.0 \% \mathrm{w} / \mathrm{w})$ and GOD $(2.0 \% \mathrm{w} / \mathrm{w})$, as shown in Figure 4, has the greatest sensitivity of $4.0 \mu \mathrm{A} / \mathrm{mM}$, more than 1.36 times the other biosensors.
Table I The sensitivity $(n=5)$ of the biosensor at different combinations of glucose oxidase (GOD) loading and multiwalled carbon nanotubes (MWCNT) loading

\begin{tabular}{lllll}
\hline Biosensor & $\begin{array}{l}\text { MWCNT } \\
\text { (\%) }\end{array}$ & $\begin{array}{l}\text { GOD } \\
(\%)\end{array}$ & $\begin{array}{l}\text { Sensitivity } \\
(\mu \mathrm{A} / \mathrm{mM})\end{array}$ & $\begin{array}{l}\text { Relative } \\
\text { SD }\end{array}$ \\
\hline 1 & 18.0 & 2.0 & $4.13 \pm 0.14$ & $3.4 \%$ \\
2 & 18.5 & 1.5 & $3.02 \pm 0.11$ & $3.6 \%$ \\
3 & 19.0 & 1.0 & $2.05 \pm 0.07$ & $3.4 \%$ \\
4 & 19.5 & 0.5 & $2.01 \pm 0.08$ & $4.0 \%$ \\
\hline
\end{tabular}

Therefore, the combination of $18.0 \% \mathrm{w} / \mathrm{w}$ of MWCNT and $2.0 \% \mathrm{w} / \mathrm{w}$ of GOD is considered as the optimum combination for constructing glucose biosensor in this study.

The reproducibility in the construction of the biosensor was evaluated from standard deviation of biosensor sensitivity. As shown in Table 1, the relative standard deviation of biosensor sensitivity indicated a batch reproducibility of biosensor construction of about $4 \%(n=5)$.

Although the glucose biosensor of the GlucoWatch has a linear $\left(\mathrm{r}^{2} \sim 0.98\right)$ glucose response range of $0-28 \mathrm{mM}$ which is larger than the one in this study $\left(\mathrm{r}^{2} \sim 1.00,0-4 \mathrm{mM}\right)$, the amount of transdermal glucose extraction by reverse iontophoresis are several orders of magnitude lower than those present in the blood $(\sim 5 \mu \mathrm{M}$ vs $\sim 5 \mathrm{mM}){ }^{28}$ Therefore, our glucose biosensor can cover the concentrations of the transdermally extracted glucose and be useful in a clinical setting.

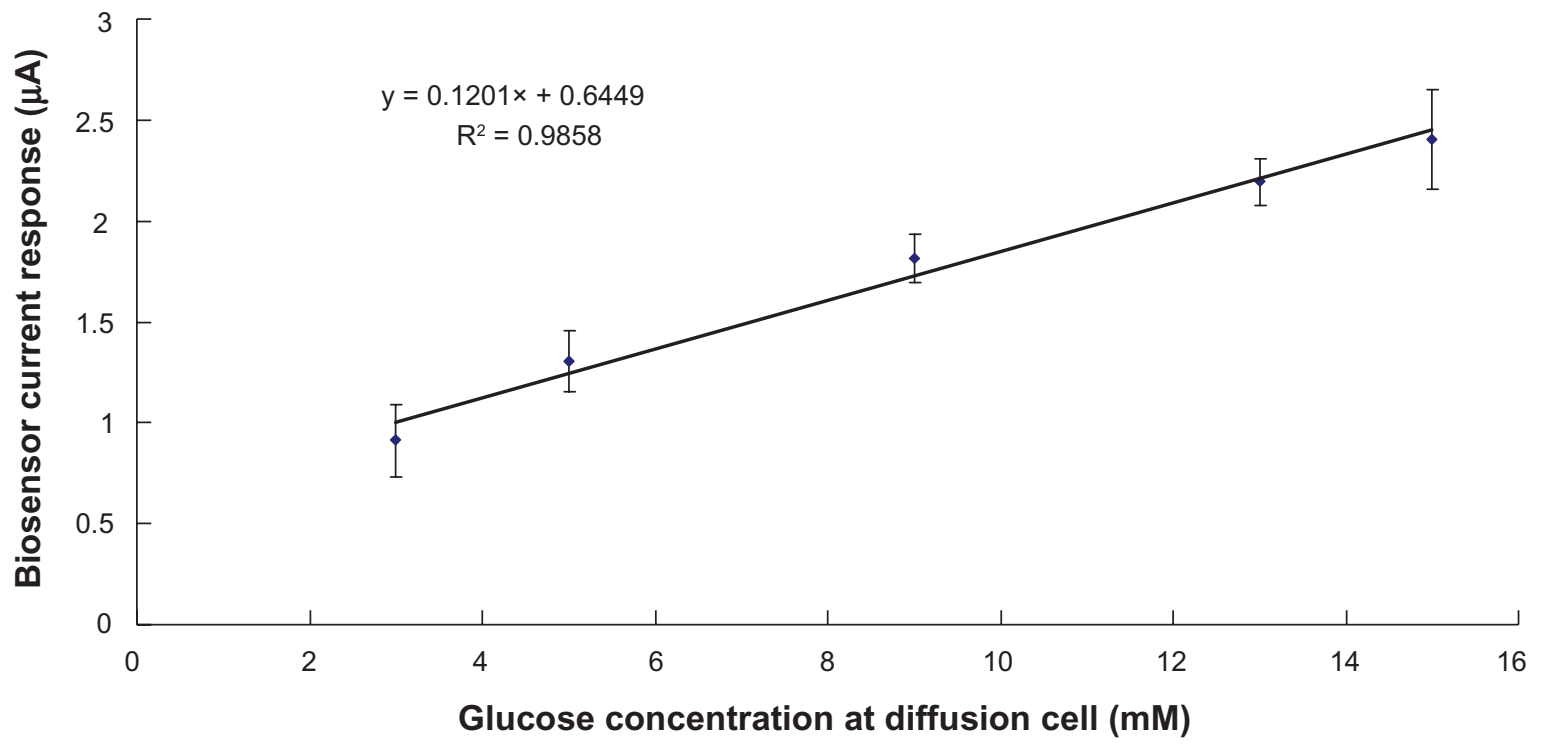

Figure 5 Evaluation of the biosensor for noninvasive glucose measurement by reverse iontophoresis. An excellent linear relationship $\left(r^{2}=0.986\right)$ between the biosensor current response and glucose concentration in diffusion cell was found. Data $(n=5)$ was obtained from biosensor with the optimum combination of MWCNT (I8.0\% w/w) and GOD $(2.0 \% \mathrm{w} / \mathrm{w})$. The diffusion cell was filled with an electrolyte solution comprising $0.1 \mathrm{M}$ phosphate buffer ( $\mathrm{pH} 7.0)$ and 3-15mM glucose. Abbreviations: GOD, glucose oxidase; MWCNT, multiwalled carbon nanotubes. 


\section{The use of the biosensor for noninvasive glucose measurement by reverse iontophoresis}

The biosensor, with the optimum combination of MWCNT $(18.0 \% \mathrm{w} / \mathrm{w})$ and GOD $(2.0 \% \mathrm{w} / \mathrm{w})$, coupled to our custom-developed reverse iontophoresis device ${ }^{34}$ has been tested in this study. Transmembrane (the membrane of the diffusion cell) glucose extraction, achieved by means of the reverse iontophoresis, was then quantified by the biosensor. The magnitude of the biosensor current response was plotted against the glucose concentration inside the diffusion cell (see Figure 5). In order to simulate hypoglycemia, normal and hyperglycemia situations, glucose concentrations of $3 \mathrm{mM}, 5 \mathrm{mM}$ and $15 \mathrm{mM}$ was chosen respectively for testing inside the diffusion cell. An excellent linear relationship $\left(r^{2}=0.99\right)$ was found between the diffusion cell glucose concentration (3-15 $\mathrm{mM}$ ) and biosensor current response. Based on the results, our glucose biosensor was accurate enough to be used to measure glucose levels in both condition of hypoglycemia and hyperglycemia, as opposed to GlucoWatch ${ }^{\circledR}$ 's unreliability in detecting hypoglycemia and hyperglycemia. ${ }^{45}$

\section{Conclusion}

A simple, low-cost carbon nanotube composite-based glucose biosensor with low oxidation potential and high sensitivity was developed in this study. The use of the biosensor incorporated with reverse iontophoresis for noninvasive glucose determination at glucose range for hypoglycemia, normal and hyperglycemia situations were also demonstrated to be successful and potentially useful in clinical setting, better than the presently commercialized product.

\section{Acknowledgments}

This work was supported by grants (NSC 98-2221-E-260002- and NSC 98-2221-E-260-024-MY3) from National Science Council, Taiwan, Republic of China. Also, this work was partially supported by grant (98A032) from the National Chi Nan University and Puli Christian Hospital, Taichung, Taiwan, Republic of China.

\section{Disclosures}

The authors report no conflicts of interest in this work.

\section{References}

1. Moore RR, Banks CE, Compton RG. Basal plane pyrolytic graphite modified electrodes: comparison of carbon nanotubes and graphite powder as electrocatalysts. Anal Chem. 2004;76:2677-2682.
2. Gong K, Zhang M, Yan Y, et al. Sol-gel-derived ceramic-carbon nanotube nanocomposite electrodes: tunable electrode dimension and potential electrochemical applications. Anal Chem. 2004;76:6500-6505.

3. Lin Y, Rao AM, Sadanadan B, et al. Functionalizing multi-walled carbon nanotubes with aminopolymers. J Phys Chem B. 2002; 106:1294-1298.

4. Jiang K, Eitan A, Schadler LS, et al. Selective attachment of gold nanoparticles to nitrogen-doped carbon nanotubes. Nano Lett. 2003;3:275-277.

5. Eitan A, Jiang KY, Dukes D, et al. Surface modification of multiwalled carbon nanotubes: toward the tailoring of the interface in polymer composites. Chem Mater. 2003;15:3198-3201.

6. Zhang MG, Smith A, Gorski W. Carbon nanotube-chitosan system for electrochemical sensing based on dehydrogenase enzymes. Anal Chem. 2004;76:5045-5050.

7. Zhao Q, Gan Z, Zhuang Q. Electrochemical sensors based on carbon nanotubes. Electroanal. 2002;14:1609-1613.

8. Li N, Wang J, Li M. Electrochemistry at carbon nanotube electrodes. Rev Anal Chem. 2003;22:19-34.

9. Jiang LY, Wang RX, Li XM, et al. Electrochemical oxidation behavior of nitrite on a chitosan-carboxylated multiwall carbon nanotube modified electrod electrochem. Electrochem Commun. 2005;597:597-601.

10. Degim IT, Ilbasmis S, Dundaroz R, Oguz Y. Reverse iontophoresis: a noninvasive technique for measuring blood urea level. Pediatr Nephrol. 2003;18:1032-1037.

11. Pitzer KR, Desai S, Dunn T, et al. Detection of hypoglycaemia with the GlucoWatch biographer. Diabetes Care. 2001;24:881-885.

12. Potts RO, Tamada JA, Tierney MJ. Glucose monitoring by reverse iontophoresis. Diabetes Metab Res Rev. 2002;18:S49-S53.

13. Rao G, Guy RH, Glikfeld P, et al. Reverse iontophoresis: noninvasive glucose monitoring in vivo in human. Pharm Res. 1995;12:1869-1873.

14. Tamada JA, Garg S, Jovanovic L, et al. Noninvasive glucose monitoring: comprehensive clinical results. Cygnus Research Team. JAMA. 1999; 282:1839-1844.

15. Tierney MJ, Tamada JA, Potts RO, et al. Clinical evaluation of the GlucoWatch ${ }^{\circledR}$ biographer: a continual, non-invasive glucose monitor for patients with diabetes. Biosens Bioelectron. 2001;16:621-629.

16. Diabetes Research in Children Network (DirecNet) Study Group. Accuracy of the GlucoWatch G2 Biographer and the continuous glucose monitoring system during hypoglycemia: experience of the Diabetes Research in Children Network. Diabetes Care. 2004;27:722-726.

17. Garg SK, Potts RO, Ackerman NR, et al. Correlation of fingerstick blood glucose measurements with GlucoWatch biographer glucose results in young subjects with type 1 diabetes. Diabetes Care. 1999;22:1708-1714.

18. Tierney MJ, Garg S, Ackerman NR, et al. Effect of acetaminophen on the accuracy of glucose measurements obtained with the GlucoWatch biographer. Diabetes Technol Ther. 2000;2:199-207.

19. Eastman RC, Chase HP, Buckingham B, et al. Use of the GlucoWatch biographer in children and adolescents with diabetes. Pediatr Diab. 2002;3:127-134.

20. Gandrud LM, Paguntalan HU, Van Wyhe MM, et al. Use of the Cygnus GlucoWatch biographer at a diabetes camp. Pediatrics. 2004;113:108-111.

21. Nunnold T, Colberg SR, Herriott MT, Somma CT. Use of the noninvasive GlucoWatch Biographer during exercise of varying intensity. Diabetes Technol Ther. 2004;6:454-462.

22. Sieg A, Guy RH, Delgado-Charro MB. Noninvasive glucose monitoring by reverse iontophoresis in vivo: application of the internal standard concept. Clin Chem. 2004;50:1383-1390.

23. Dunn TC, Eastman RC, Tamada JA. Rates of glucose change measured by blood glucose meter and the GlucoWatch Biographer during day, night, and around mealtimes. Diabetes Care. 2004;27:2161-2165.

24. Tsalikian E, Kollman C, Mauras N, et al. GlucoWatch G2 Biographer alarm reliability during hypoglycemia in children. Diabetes Technol Ther. 2004;6:559-566. 
25. Hathout E, Patel N, Southern C, et al. Home use of the GlucoWatch G2 biographer in children with diabetes. Pediatrics. 2005;115:662-666.

26. Fiallo-Scharer R, for Diabetes Research in Children Network Study Group. Eight-point glucose testing versus the continuous glucose monitoring system in evaluation of glycemic control in Type 1 diabetes. J Clin Endocrinol Metab. 2005;90:3387-3391.

27. Buckingham B, Block J, Burdick J, et al. Diabetes Research in Children Network, response to nocturnal alarms using a real-time glucose sensor. Diabetes Technol Ther. 2005;7:440-447.

28. Tierney MJ, Jayalakshmi Y, Parris NA, et al. Design of a biosensor for continual, transdermal glucose monitoring. Clin Chem. 1999;45:1681-1683.

29. Kurnik RT, Berner B, Tamada J, Potts RO. Design and simulation of a reverse lontophoretic glucose monitoring device. J Electrochem Soc. 1998;145:4119-4125.

30. Kurnika RT, Oliver JJ, Waterhouse SR, et al. Application of the Mixtures of Experts algorithm for signal processing in a noninvasive glucose monitoring system. Sensor Actuat B-Chem. 1999;60:19-26.

31. Tamada JA, Bohannon NJ, Potts RO. Measurement of glucose in diabetic subjects using noninvasive glucose extraction. Nat Med. 1995; 1:1198-1201.

32. Ching CTS, Sun TP, Huang SH, et al. A mediated glucose biosensor incorporated with reverse iontophoresis function for noninvasive glucose monitoring. Ann Biomed Eng. (DOI: 10.1007/s10439-0109918-4), 2010.

33. Ching CTS, Connolly P. A novel diffusion cell ideal for the study of membrane extraction/permeation processes and for device/sensor development. Sensor Actuat B-Chem. 2008;129:30-34.

34. Ching CTS, Camilleri I, Connolly P. A low-cost, programmable device for versatile current delivery in iontophoresis applications. Sensor Actuat B-Chem. 2005;106:534-540.
35. De La Guardia M. Biochemical sensors: the state of art. Microchim Acta. 1995;120:243-255.

36. Khan GF, Wernet W. Design of enzyme electrodes for extended use and storage life. Anal Chem. 1997;69:2682-2687.

37. Galan-Vidal CA, Munoz J, Dominguez C, et al. Glucose biosensor strip in a three electrode configuration based on composite and biocomposite materials applied by planar thick film technology. Sensor Actuat B-Chem. 1998;52:257-263.

38. Angerstein-Kozlowska H. Comprehensive treatise of electrochemistry. New York: Plenum Press; 1984.

39. Jager A, Bilitewski U. Screen printed enzyme electrode for the determination of lactose. Analyst. 1994;119:1251-1255.

40. White SF, Tothill IE, Newman JD, Turner APF. Development of a mass-producible glucose biosensor and flow-injection analysis system suitable for on line monitoring during fermentations. Anal Chim Acta. 1996;321:165-172.

41. Nagata R, Yokoyama K, Clark SA, Karube I. A glucose biosensor fabricated by the screen printing technique. Biosensens Bioelectron. 1995; 10:261-267.

42. Lambrechts M, Sansen W. Biosensors: microchemical devices. Bristol: IOP publishing; 1992.

43. Gunther A, Bilitewski U. Characterization of inhibitors of acetylcholinesterase by an automated amperometric flow-injection system. Anal Chim Acta. 1995;300:117-125.

44. Antiochia R, Gorton L. Development of a carbon nanotube paste electrode osmium polymer-mediated biosensor for determination of glucose in alcoholic beverages. Biosens Bioelectron. 2007;22:2611-2617.

45. Chase HP, Beck R, Tamborlane W, et al. A randomized multicenter trial comparing the GlucoWatch biographer with standard glucose monitoring in children with type 1 diabetes. Diabetes Care. 2005;28:1101-1106.
International Journal of Nanomedicine

\section{Publish your work in this journal}

The International Journal of Nanomedicine is an international, peerreviewed journal focusing on the application of nanotechnology in diagnostics, therapeutics, and drug delivery systems throughout the biomedical field. This journal is indexed on PubMed Central,

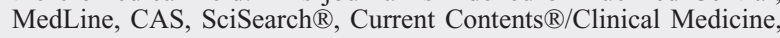

\section{Dovepress}

Journal Citation Reports/Science Edition, EMBase, Scopus and the Elsevier Bibliographic databases. The manuscript management system is completely online and includes a very quick and fair peer-review system, which is all easy to use. Visit http://www.dovepress.com/ testimonials.php to read real quotes from published authors. 